\title{
A telehealth program for self-management of COPD exacerbations and promotion of an active lifestyle: a pilot randomized controlled trial
}

This article was published in the following Dove Press journal:

International Journal of COPD

9 September 2014

Number of times this article has been viewed

\author{
Monique Tabak ${ }^{1,2}$ \\ Marjolein Brusse-Keizer ${ }^{3}$ \\ Paul van der Valk ${ }^{3,4}$ \\ Hermie Hermens ${ }^{1,2}$ \\ Miriam Vollenbroek- \\ Hutten ${ }^{1,2}$ \\ 'Telemedicine Group, Roessingh \\ Research and Development, \\ ${ }^{2}$ Telemedicine Group, University \\ of Twente, ${ }^{3}$ Department of Pulmonary \\ Medicine, Medisch Spectrum Twente, \\ ${ }^{4}$ Medical School Twente, Medisch \\ Spectrum Twente, Enschede, the \\ Netherlands
}

\begin{abstract}
The objective of this pilot study was to investigate the use of and satisfaction with a chronic obstructive pulmonary disease (COPD) telehealth program applied in both primary and secondary care. The program consisted of four modules: 1) activity coach for ambulant activity monitoring and real-time coaching of daily activity behavior, 2) web-based exercise program for home exercising, 3) self-management of COPD exacerbations via a triage diary on the web portal, including self-treatment of exacerbations, and 4) teleconsultation. Twenty-nine COPD patients were randomly assigned to either the intervention group (telehealth program for 9 months) or the control group (usual care). Page hits on the web portal showed the use of the program, and the Client Satisfaction Questionnaire showed satisfaction with received care. The telehealth program with decision support showed good satisfaction (mean 26.4, maximum score 32 ). The program was accessed on $86 \%$ of the treatment days, especially the diary. Patient adherence with the exercise scheme was low (21\%). Health care providers seem to play an important role in patients' adherence to telehealth in usual care. Future research should focus on full-scale implementation in daily care and investigating technological advances, like gaming, to increase adherence.
\end{abstract}

Keywords: COPD, physical activity, exacerbations, telehealth, self-management

\section{Introduction}

Chronic obstructive pulmonary disease (COPD) is characterized by chronic airflow limitation of the airways, and has a large effect on physical, psychological, and social functioning. ${ }^{1,2}$ In patients with COPD, dyspnea (during exertion) is one of the major symptoms, which leads to an inactive lifestyle. As inactivity is associated with poor prognosis, several (inter)national guidelines advise promoting physical activity in daily life. ${ }^{3,4}$ In addition exacerbations have a serious negative impact on patients' quality of life and result in prolonged activity limitation. ${ }^{5,6}$

The optimal management of COPD is complex, due to a heterogeneous picture of progressive deterioration, as well as the great variation in symptoms, functional limitations, and well-being that patients with COPD experience. ${ }^{5,7,8}$ Multidisciplinary integrated programs have been shown to be able to optimize quality of life and exercise tolerance, ${ }^{9}$ especially when containing an exercise program. ${ }^{10}$ However, these programs are advised to be more individually tailored and accessible by the patient when they need it most. ${ }^{11,12}$ Recent technological advances in health care could supply this need by telemonitoring of activity and symptoms, and provide treatment in daily life.

For example, Nguyen et al incorporated technology in their dyspnea selfmanagement program, to support early recognition of worsening symptoms through
Correspondence: Monique Tabak Telemedicine Group, University of Twente, Drienerlolaan 5, PO Box 217, Enschede $7500 \mathrm{AE}$, the Netherlands

Tel +31534892762

Fax +3I 534340849

Emailm.tabak@utwente.nl 
real-time monitoring, quick feedback, and access to information and support. ${ }^{13}$ In a study by Jensen et al, a telehealth monitor collected and transmitted data about the patient to a web-based portal or electronic health care record, while professionals could monitor progress and training inputs and provide advice to the patient. ${ }^{14}$ Active involvement of a case manager is needed for final interpretation of monitoring data or feedback to the patient, which might slow the care process. We would assume that by using decisionsupport technology and automated feedback to the patient, telehealth interventions can contribute to more effective and efficient quality health care.

The potential of telehealth regarding health care utilization and costs, acceptability, or clinical characteristics is the starting point for development of interventions. However, reviews show that the overall benefits are not yet proven, ${ }^{15,16}$ and limited evidence has been reported for their value in chronic disease management. ${ }^{17}$ Multimodal telehealth programs that monitor patient behavior and symptoms in daily life to deliver intensive personal automated feedback to improve activity behavior, facilitate home exercising, and empower patients in self-care and disease management have not been investigated at all.

In this paper, we describe a technology-supported care program that supports the treatment of COPD patients through self-treatment of exacerbations, and promotion of an active lifestyle by real-time coaching and home exercising via a web portal. This program was applied as blended care, ie, implemented within usual care - primary and secondary - to explore the potential for daily health care practice. The care was individualized by health care professionals based on the patient characteristics and progress of every individual patient in order to resemble future telemedicine use in daily practice as much as possible. Understanding the use of and adherence with such an intervention is essential for future telemedicine interventions. ${ }^{18}$ Therefore, we performed a pilot study to investigate the use of a telehealth program in detail and explore the satisfaction experienced with received care. As this pilot study was run as a miniature randomized controlled trial, we also explored the clinical measures of the telehealth program compared to usual care in terms of hospitalizations, health status, exercise capacity, symptoms, activity level, and quality of life.

\section{Materials and methods}

In this pilot study, we performed a miniature randomized controlled trial. Patients were eligible for inclusion if they fulfilled the COPE II (Study of the effects of self-treatment and an exercise program within a self-management program in outpatients with COPD) study criteria, as described previously. ${ }^{19}$ These include, eg, no exacerbation in the month prior to enrollment and three or more exacerbations or one hospitalization for respiratory problems in the 2 years preceding study entry. Besides these COPE II criteria, patients should also have a computer with Internet access at home. The study took place in the Medisch Spectrum Twente Hospital and primary care physiotherapy practices in Enschede, the Netherlands, between December 2011 and July 2013. Patients started study participation in April, July, or September 2012, and the duration of the study was 9 months. The study was approved by the Twente Medical Ethical Committee and registered in The Netherlands Trial Register (NTR3072).

Sample size was based upon the estimated number of patients that could be included within the recruitment period and the availability of technology. Patients were randomized using a computer-generated randomization list (Blocked Stratified Randomization version 5; Steven Piantadosi), where randomization was applied in random blocks of two and four. Participants were allocated by a data manager in order of inclusion following the randomization list, placed in a sealed envelope.

\section{Intervention group: telehealth program}

The framework for the technology-supported care program, called the Condition Coach, was provided by previous work on self-management programs, ${ }^{19}$ home-exercise programs, ${ }^{20}$ changing activity behavior, ${ }^{21,22}$ and telemedicine interventions. $^{22,23}$ The Condition Coach consists of four modules (Figure 1):

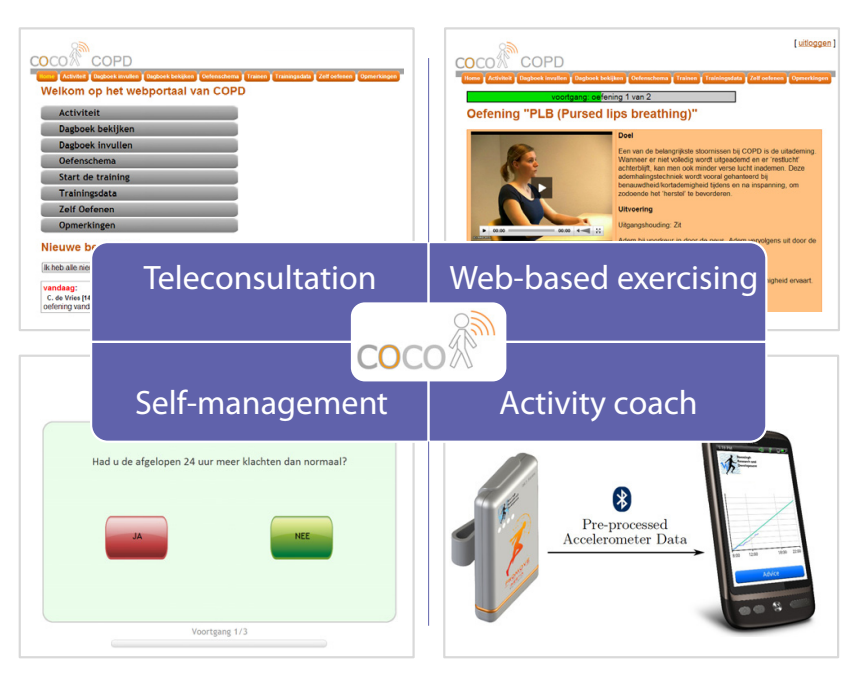

Figure I The telehealth-program modules. 
1. A web-based exercise program on the web portal, originating from the COPE II and Pulmofit (Study of the effect of immediate reactivation on length of stay in the hospital in patients with an exacerbation of COPD) studies. ${ }^{20,24}$ This included breathing exercises, relaxation, mobilization, resistance and endurance training, and mucus clearance. For every individual patient, exercise schemes were created by the patient's physiotherapist via the web portal. A scheme represents which exercises should be performed by the patient for which day, and which part of the day. Every exercise consists of a text description and movie. The patient is able to log in at home, follow the exercise scheme, execute the exercises, and provide feedback to the physiotherapist. Apart from the exercise scheme, patients can perform an extra exercise with the "additional exercises" option. Before the start of the program, patients received instructions from the primary care physiotherapist explaining the web portal and for performing baseline measures. There was no standardized exercise protocol: the physiotherapist could freely select the exercises for each patient for the online exercise program. This exercise program could be adapted during the intervention period following the progress of the patient at the discretion of the therapist. Both primary and secondary care professionals could supervise the patient at a distance by checking progress on the web portal.

2. Activity coach for ambulant activity registration and realtime feedback to improve daily activity. The activity coach consists of an accelerometer-based activity sensor (Inertia Technology, Enschede, the Netherlands) and a smartphone (Desire S; HTC, New Taipei, Taiwan). The smartphone shows the measured activity cumulatively in a graph, together with the cumulative activity the users should aim for: the reference activity line. In addition, the users received motivational cues during the day for awareness and extra motivation. These messages were based on the activity of the last 2 hours and of the day so far. Each cue provided a summary of the activity behavior and advice on how to continue the activity behavior, eg, "You have been very active today, but took some rest now. Keep on going like this, and keep in mind your activity balance." At the end of the day, the patient received a summary of their activity behavior (eg, "You were clearly less active today. Discuss this with your physiotherapist"). The participant's measured activity levels were also displayed on the web portal. The physiotherapist determined for each individual patient how and when the activity-coach module was used.
Likewise, the reference activity line could be completed on the web portal, without restrictions, although the physiotherapist could use activity-monitoring data of the patient as a starting point.

3. A self-management module on the web portal that enables patients to treat exacerbations themselves, without the intervention of a health care professional. This self-treatment protocol has been described in detail previously. ${ }^{19}$ Every day, participants were asked to fill in the diary on the web portal, which is the digital version of the diary used by Effing et al. ${ }^{19}$ The decision tree of this diary was translated into a decision-support system that automatically formed advice to start medication in cases of worsening of the clinical condition. Before the start of the program, participants had to attend two 90-minute self-management teaching sessions given by a nurse practitioner, to learn how to complete the daily diary. ${ }^{19}$ Patients were also educated in early recognition of exacerbations and in starting standardized treatment in the case of an exacerbation. After successful completion of the teaching sessions, patients received recipes for their medication. In the case of an exacerbation, a standardized intervention was initiated: prednisolone $30 \mathrm{mg}$ for 7 days, and when indicated in combination with antibiotics (amoxicillin/clavulanic acid [Augmentin ${ }^{\circledR}$ 500/125 mg; GlaxoSmithKline, Brentford, UK]) three times daily for a period of 7 days or (in the case of hypersensitivity) doxycycline $100 \mathrm{mg}$ for a period of 10 days. ${ }^{19}$ Patients were instructed to call the study office if they desired assistance, and if needed, a consultation with a chest physician or nurse practitioner was scheduled accordingly. These health care professionals could access the diary data via the web portal.

4. Teleconsultation module for comments and asking questions of the patient's primary care physiotherapist and vice versa, via the web portal. These include both general and specific comments/questions concerning certain exercises in the patient's exercise scheme.

\section{Control group: usual care}

Participants in the control group received only usual care. This meant that in the case of an impending exacerbation, the participants had to contact their medical doctor as usual. This could be either the general practitioner or chest physician, or in some cases the emergency room department. Patients in the control group were allowed to attend regular physiotherapy sessions if this was prescribed as part of usual care. 


\section{Outcome measures}

In both the intervention and control groups, questionnaires were administered at T0 (inclusion), T1 (1 month), T2 (3 months), T3 (6 months), and T4 (9 months). For the intervention group, use of the application was registered by the system between the T0 measurement and the T4 measurement. Use of the application was calculated for all patients, including patients that did not complete the study participation. Adherence to the online diary was calculated by dividing the number of diary fill-outs by the number of treatment days. Adherence to the exercise scheme was calculated by dividing the number of schemes that were prescribed by the number of schemes performed. In both groups, satisfaction with received care was measured by the Client Satisfaction Questionnaire 8. The total score range is $8-32$, and a higher score indicates a higher degree of client satisfaction.

Regarding the clinical outcome measures, the number of hospitalizations, length of stay, and emergency department visits were registered during the 9-month follow-up period in both groups. The decision-support diary automatically identified exacerbations following previously described criteria $^{19}$ for the intervention group, while the control group filled in a paper version of the diary. The activity sensor of the activity coach was used for registration of activity levels in both groups, expressed in the time integral of the modulus of accelerometer output (IMA; counts per minute). ${ }^{25}$ A measurement day should have consisted of 6 or more hours. The Baecke Physical Activity Questionnaire was used for assessing self-perceived activity levels. Additional outcome measures to evaluate the clinical changes were: exercise tolerance (6-minute walk test [6MWT]), fatigue (Multidimensional Fatigue Inventory 20), health status (Clinical COPD Questionnaire), dyspnea (Medical Research Council scale, as defined in the Dutch physiotherapy guidelines ${ }^{3}$ ) and quality of life (EuroQol-5D). Questionnaires were administered in both groups from T0 to T4; 6MWT was not performed at T1.

\section{Statistical methods}

A standard package was used (SPSS 19.0; IBM, Armonk, NY, USA). For baseline demographics, differences between the groups were analyzed using the independent $t$-test (in the case of normal distribution) or Wilcoxon's rank-sum test. For comparing two categorical variables, Pearson's $\chi^{2}$ or Fisher's exact test was used. Alpha was set at 0.05 .

To present the outcome measures over time in both groups, a mixed-model analysis for repeated measures was performed (intention to treat). Time of measurement (T0-T2) was used as a within-subjects factor and group (telehealth or usual care) as a between-subjects factor. The clinical outcomes were presented as means and standard error. As this was a miniature randomized controlled trial without power analysis, no statistical tests were performed.

\section{Results}

Although 101 patients fulfilled the COPE II study criteria, only 29 patients $(29 \%)$ were able and willing to participate.

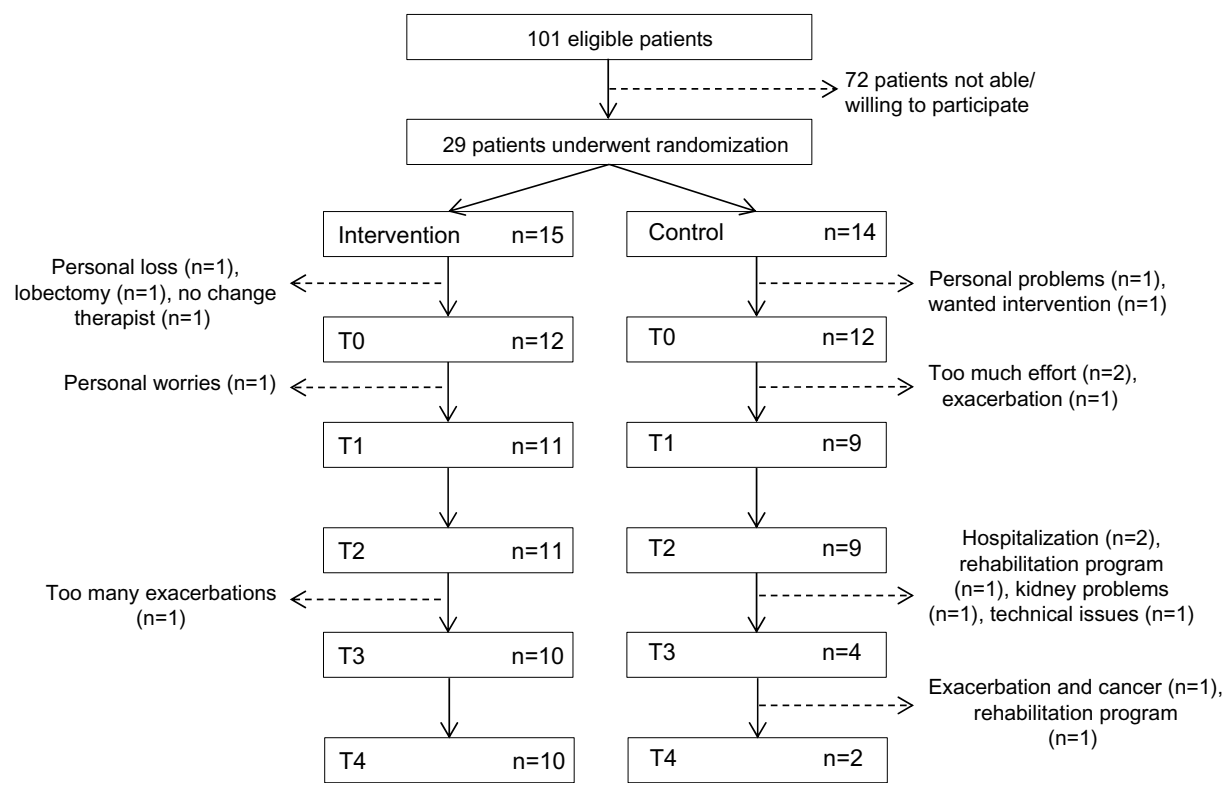

Figure 2 Flowchart for recruitment, randomization, and dropout.

Abbreviations: T0, inclusion; TI, I month; T2, 3 months; T3, 6 months; T4, 9 months. 
The reason for not participating was that patients did not fulfill the additional criterion of having a computer with Internet access at home. Figure 2 shows the progression of the participants through the study. A large number of patients were not able or willing to continue study participation: $33 \%$ in the intervention group and $86 \%$ in the control group. Although some patients in the intervention group quit the physiotherapy modules (exercising and activity coach) due to weak $(n=1,<T 1)$ or unstable condition $(n=1,<T 2)$ and personal circumstances $(n=2,<T 4)$, they persisted in using the web portal and triage diary till T4. Table 1 shows the baseline characteristics for both the intervention and control groups. There was a significant difference found for baseline dyspnea levels between groups $(P=0.03)$, showing better clinical measures in the telehealth group.

\section{Use and satisfaction}

Figure 3 shows the percentage of treatment days that patients visited the web portal per intervention month. The web portal was highly used over time, and no large changes were observed between months (Figure 3 ).

Table 2 shows in more detail the specific use of the web portal per patient. In a number of patients, the intervention period (T0-T4) lasted more than 9 months. The web portal was used in $86.4 \%$ of days during the intervention, in which the triage diary was the mostly used module (median $82.8 \%$ ). In total, 569 exercise schemes were prescribed to the patients, of which 127 schemes were completely performed (median adherence $21.0 \%$ ). A total of 1,110 exercises were prescribed to the patients within the exercise schemes. Additionally,
543 exercises were performed independently (additional exercises option). Patients 5, 9, 10, and 12 stopped using the exercise and activity modules, but continued using the diary.

In the intervention group, the activity coach-module was used for 299 days in total, of which 132 days were in the monitoring mode and 167 days in the feedback mode. Although both monitoring and feedback modes were used, the activity coach was rarely used outside of the measurement weeks (T0-T4). The use of the web portal differed greatly between patients; some used the diary almost every day, other only half of the days. Some performed regular additional exercises, while others did not use the exercise module at all.

Figure 4 shows the number of patients who received exercise schemes from their physiotherapist over time. Eight of 12 patients received an exercise scheme from the therapist, and the number of prescribed schedules declined over time. The average number of schemes prescribed by the physiotherapists to individual patients tended to increase in the first half-year. In the first month, only one patient received an exercise scheme.

Satisfaction with received care (maximum score 32), as obtained by repeated measures (mean [standard error]) was 26.4 (1.3) for the telehealth group and 30.4 (1.5) for the usualcare group at T1. At T2, this was 26.3 (1.3) for the telehealth group and 29.9 (1.4) for the usual-care group.

\section{Clinical measures}

Table 3 describes the number and duration of hospitalizations, emergency room visits, and number of exacerbations

Table I Baseline demographics and clinical characteristics

\begin{tabular}{|c|c|c|c|c|c|c|}
\hline Variable & $\mathbf{n}$ & Telehealth & $\mathbf{n}$ & Usual care & $95 \% \mathrm{Cl}$ & $P$ \\
\hline Age (years) & 12 & $64.1 \pm 9.0$ & 12 & $62.8 \pm 7.4$ & -5.7 to -8.2 & 0.71 \\
\hline Male/female & 12 & $6 / 6$ & 12 & $6 / 6$ & & 1.0 \\
\hline $\mathrm{FEV}_{1} \%$ predicted ${ }^{\#}$ & 12 & $50.0(33.3-61.5)$ & 12 & $36.0(26.0-53.5)$ & & 0.25 \\
\hline BMI $\left(\mathrm{kg} / \mathrm{m}^{2}\right)$ & 12 & $25.3 \pm 4.2$ & 12 & $28.2 \pm 4.6$ & -6.6 to -0.9 & 0.126 \\
\hline Exercise capacity (6MWT, m) & 11 & $409.5 \pm 111.6$ & 7 & $313.0 \pm 79.4$ & -6.8 to -199.7 & 0.065 \\
\hline Dyspnea (MRC scale) & 10 & $3.0(2.0-3.3)$ & 11 & $4.0(3.0-4.0)$ & & $0.032 *$ \\
\hline Health status (CCQ) & 11 & $2.0 \pm 1.0$ & 11 & $2.7 \pm 0.8$ & -1.5 to -0.1 & 0.079 \\
\hline Fatigue (MFI)\# & 11 & $12.0(10.0-16.0)$ & 11 & $16.0(11.0-20.0)$ & & 0.26 \\
\hline \multicolumn{7}{|l|}{ Quality of life (EQ-5D) } \\
\hline VAS & 11 & $64.1 \pm 15.9$ & 11 & $65.0 \pm 12.0$ & -13.5 to -11.7 & 0.88 \\
\hline Index & 11 & $0.75 \pm 0.09$ & 9 & $0.69 \pm 0.14$ & -0.05 to -0.17 & 0.28 \\
\hline Subjective activity (BPAQ) & 10 & $7.1 \pm 1.4$ & 10 & $6.2 \pm 1.3$ & -0.34 to 2.25 & 0.139 \\
\hline Smokers/nonsmokers & 11 & $4 / 7$ & 12 & $4 / 8$ & & 1.0 \\
\hline Employed/unemployed & 12 & $5 / 7$ & 11 & $2 / 9$ & & 0.371 \\
\hline
\end{tabular}

Notes: Data shown as mean \pm standard deviation with confidence interval $(\mathrm{Cl})$ except stated otherwise. $* \mathrm{P}<0.05$; ${ }^{*}$ nonparametric test, showing the median and interquartile range.

Abbreviations: 6MWT, 6-minute walking test; BMI, body mass index (in kg/m2); BPAQ, Baecke Physical Activity Questionnaire; CCQ, clinical COPD questionnaire; COPD, chronic obstructive pulmonary disease; EQ-5D, EuroQol; FEV scale); MRC, Medical Research Council; VAS, Visual Analogue Scale. 


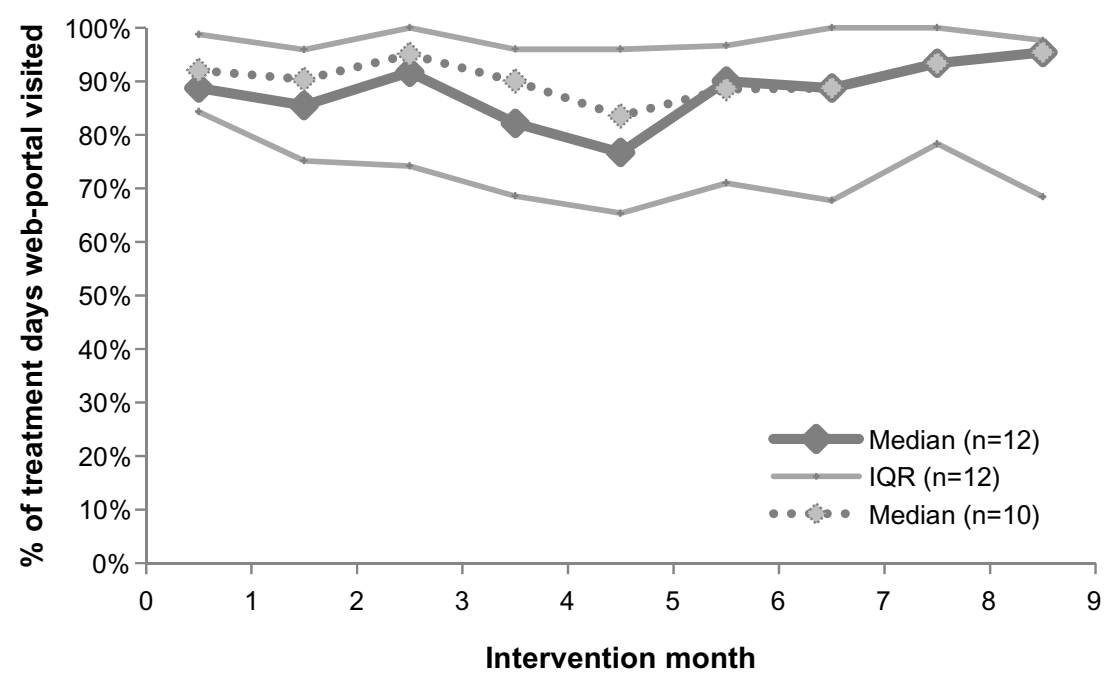

Figure 3 Median number of days (with interquartile range [IQR]) that the web portal was visited

Note: Dotted line, patients that completed the intervention $(n=10)$.

in COPD. For the telehealth group, the decision-support diary identified exacerbations, as described previously. ${ }^{19}$ The total telehealth group reported 33 exacerbations (median 2.0, interquartile range 1.0-3.0) for which medication was required, of which one patient had eleven exacerbations according to the COPE II criteria. A number of these exacerbations occurred within 28 days of the previous exacerbation. Exacerbation data were not available for the control group. The telehealth group had in total four hospitalizations for COPD with a median duration of 5.5 days, while the control group had in total five hospitalizations for COPD with a median duration of 7.0 days. Table 4 shows the clinical measures obtained from the repeated measures. Data in Table 4 are descriptive only, and present T0-T2.

\section{Discussion}

In this pilot study, a telehealth program was investigated within usual primary and secondary care to explore the potential for daily health care practice and to provide knowledge for the implementation of larger-scale trials. The study showed that patients were satisfied with the received care, and that parts of the program were highly used during the 9-month intervention period.

\section{Use and satisfaction}

The intervention was used on $86 \%$ of the treatment days, and this remained stable over the intervention period. This is a very high rate, as according to the World Health Organization, adherence to long-term therapy in chronic diseases averages

Table 2 Use of the intervention by the telehealth group $(n=12)$

\begin{tabular}{|c|c|c|c|c|c|c|c|c|c|c|c|c|}
\hline \multirow[t]{2}{*}{ n } & \multirow{2}{*}{$\begin{array}{l}\text { Treatment } \\
\text { days }\end{array}$} & \multirow{2}{*}{$\begin{array}{l}\% \text { of days } \\
\text { visited }\end{array}$} & \multicolumn{3}{|c|}{ Diary } & \multicolumn{4}{|c|}{ Exercise } & \multicolumn{2}{|c|}{ Activity coach } & \multirow{2}{*}{$\begin{array}{l}\text { No } \\
\text { comments }\end{array}$} \\
\hline & & & $\begin{array}{l}\text { Fill- } \\
\text { outs }\end{array}$ & Checks & Compl & Perf & $\begin{array}{l}\text { Not } \\
\text { perf }\end{array}$ & Compl & $\begin{array}{l}\text { Add } \\
\text { ex }\end{array}$ & $\begin{array}{l}\text { Visits } \\
\text { port }\end{array}$ & $\begin{array}{l}\text { Days' use activity } \\
\text { coach (monitorl } \\
\text { feedback) }\end{array}$ & \\
\hline I & 92 & $67.4 \%$ & 61 & 13 & $66.3 \%$ & - & - & - & 0 & 11 & $5(5 / 0)$ & 0 \\
\hline 2 & 347 & $94.2 \%$ & 321 & 54 & $92.5 \%$ & 48 & 72 & $40.0 \%$ & 123 & 29 & $30(8 / 22)$ & 2 \\
\hline 3 & 336 & $65.5 \%$ & 212 & 16 & $63.1 \%$ & 33 & 128 & $20.5 \%$ & 71 & 5 & $30(7 / 23)$ & 95 \\
\hline 4 & 265 & $86.8 \%$ & 227 & 61 & $85.7 \%$ & - & - & - & 0 & 21 & $28(13 / 15)$ & 0 \\
\hline 5 & 316 & $94.9 \%$ & 299 & 34 & $94.6 \%$ & - & 33 & 0 & 15 & 1 & $30(9 / 21)$ & 0 \\
\hline 6 & 253 & $93.7 \%$ & 234 & 154 & $92.5 \%$ & - & - & - & 21 & 27 & $27(20 / 7)$ & 0 \\
\hline 7 & 259 & $79.5 \%$ & 202 & 162 & $78.0 \%$ & 10 & 31 & $24.4 \%$ & 30 & 16 & $33(2 \mathrm{I} / \mathrm{I} 2)$ & 0 \\
\hline 8 & 255 & $85.9 \%$ & 204 & 28 & $80.0 \%$ & 30 & 89 & $25.2 \%$ & 283 & 19 & $38(14 / 24)$ & 0 \\
\hline 9 & 250 & $95.6 \%$ & 234 & 186 & $93.6 \%$ & - & - & - & 0 & 0 & $7(7 / 0)$ & 0 \\
\hline 10 & 296 & $59.5 \%$ & 174 & 133 & $58.8 \%$ & - & 27 & 0 & 0 & 15 & $39(8 / 31)$ & 0 \\
\hline II & 144 & $47.2 \%$ & 64 & 37 & $44.4 \%$ & 6 & 22 & $21.4 \%$ & 0 & 2 & $6(6 / 0)$ & 2 \\
\hline 12 & 254 & $87.0 \%$ & 218 & 180 & $85.8 \%$ & - & 23 & 0 & 0 & 4 & $26(14 / I 2)$ & 0 \\
\hline Median & 257 & $86.4 \%$ & 215 & 58 & $82.8 \%$ & 30 & 32 & $21.0 \%$ & 8 & 13 & $29(9 / 14)$ & 0 \\
\hline Sum & 3,067 & & 245 & 1,058 & & 127 & 425 & & 543 & 150 & $299(132 / 167)$ & 99 \\
\hline
\end{tabular}

Abbreviations: Compl, compliance; Perf, performed; Add ex, additional exercises; port, portal. 


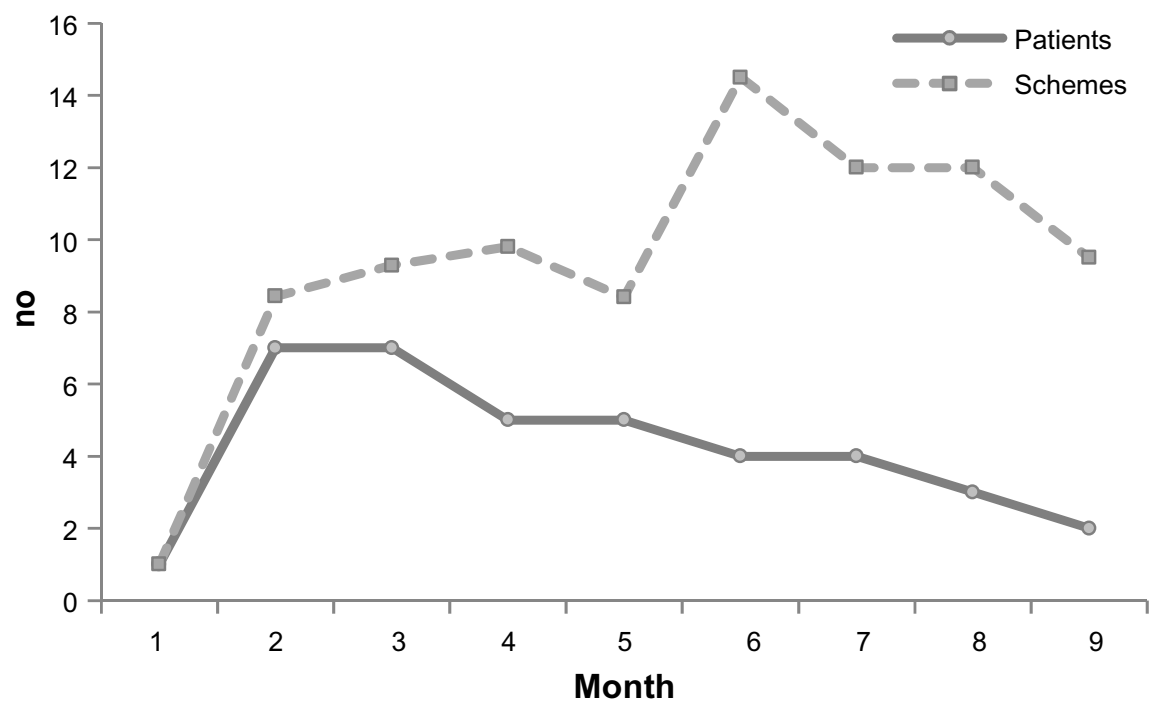

Figure 4 Number of patients who received exercise schemes from their physiotherapist (solid line), and the average number of schemes that were prescribed to these patients (dotted line) per month.

$50 \% \cdot{ }^{26}$ The high usage of the intervention especially applied to the self-management module - including self-treatment of COPD exacerbations - probably because this module incorporated influential factors for good adherence: ${ }^{27}$ the patient was actively involved in the treatment process, in which they were educated in how to recognize their symptoms, but also in the importance of treatment. In addition, the self-management course was provided by their health care professional in an interactive real-life group setting with fellow patients, and the treatment regimen was simple and straightforward. Previous research on this self-management module showed it to be a successful aspect in the treatment of COPD exacerbations, with an $85 \%$ completion rate (unpublished data ${ }^{19}$ ), comparable to our study. In that study, patients were asked to return their completed paper diary by prepaid mail to the research office at the end of each

Table 3 Number of hospitalizations, emergency room (ER) visits, exacerbations, and length of stay for the telehealth and usual groups in the study period

\begin{tabular}{lll}
\hline & $\begin{array}{l}\text { Telehealth } \\
(\mathbf{n}=\mathbf{1 2})\end{array}$ & $\begin{array}{l}\text { Usual care } \\
(\mathbf{n}=\mathbf{1 2})\end{array}$ \\
\hline Exacerbations/relapses, $\mathrm{n}$ & 33 & $\mathrm{NA}$ \\
Advice to start medication, $\mathrm{n}$ & 35 & $\mathrm{NA}$ \\
Hospitalizations for COPD, $\mathrm{n}$ & 4 & 5 \\
Hospitalizations - other, $\mathrm{n}$ & 4 & 2 \\
Length of stay, hospitalization for COPD & 22 days & 36 days \\
Median length of hospital stay for & $5.5(4.8-6.3)$ & $7.0(6.0-7.0)$ \\
COPD, days & & \\
ER visits for COPD, $\mathrm{n}$ & 5 & 5 \\
\hline
\end{tabular}

Note: Median length of stay shown with interquartile range.

Abbreviation: COPD, chronic obstructive pulmonary disease; ER, emergency room; NA, not applicable. month, and in the case of incorrect completion the patient was contacted by phone. To increase adherence to filling in our online diary even further, an option could be to apply the diary to a smartphone, where the patient automatically receives a message to fill in the diary.

In contrast to the self-management module, the use of the exercise module and the activity coach was critically low. These modules showed 1) low use by the physiotherapists, and 2) low adherence of the patients. From the experience gained in this study, several reasons can be given. Regarding the low use by the physiotherapists, one reason is that the physiotherapists did not regularly prescribe exercise schemes to the patients or incorporate the activity coach in the treatment program. Professionals are important in helping patients understand the nature of the disease and potential benefits of treatment and encouraging the development of self-management skills. ${ }^{27}$ As such, their attitude toward telehealth treatment can greatly influence the perception and adherence of the patients. In the literature, a reported problem regarding the use of telehealth by professionals is distrust in the technology due to problems with and reliability of the measurements. ${ }^{28,29}$ Another issue is that only a few patients of the health care professionals involved took part in the telehealth study, and thereby telehealth was not a part of their regular routine. Full-scale implementation in health care is needed in the future in which use and acceptance of all the users, including the health care professionals, should be investigated.

With regard to the low adherence to the exercise module by the patients, a reason could be that the technology was not 
Table 4 Clinical changes obtained from repeated measures, with standard error of the mean

\begin{tabular}{|c|c|c|c|c|c|c|}
\hline & \multicolumn{3}{|l|}{ Telehealth } & \multicolumn{3}{|l|}{ Usual care } \\
\hline & T0 & TI & T2 & T0 & TI & T2 \\
\hline Exercise capacity (6MWT, m) & $409.5(29.5)$ & NA & $412(38.7)$ & $300.1(33.6)$ & NA & $312.4(44.0)$ \\
\hline Health status (CCQ) & $2.0(0.26)$ & $1.9(0.17)$ & $1.8(0.24)$ & $2.7(0.27)$ & $2.3(0.21)$ & $2.3(0.26)$ \\
\hline \multicolumn{7}{|l|}{ Fatigue (MFI) } \\
\hline General fatigue & $12.3(1.4)$ & $11.0(1.1)$ & $10.4(1.3)$ & $15.0(1.4)$ & $13.6(1.3)$ & I3.8 (I.5) \\
\hline Physical fatigue & $12.2(3.2)$ & $11.9(3.2)$ & II.0 (3.3) & $16.5(3.2)$ & $14.4(3.2)$ & I $4.4(3.3)$ \\
\hline Reduced activity & $8.3(1.2)$ & $9.3(0.9)$ & $8.2(1.2)$ & $12.5(1.3)$ & $11.7(1.1)$ & $10.5(1.3)$ \\
\hline Reduced motivation & $9.3(1.1)$ & $7.4(0.9)$ & $7.5(1.2)$ & $9.4(1.2)$ & $8.2(1.0)$ & $8.8(1.3)$ \\
\hline Mental fatigue & $8.5(1.1)$ & $9.9(1.4)$ & $6.6(0.9)$ & $7.0(1.2)$ & $8.0(1.7)$ & $7.3(1.1)$ \\
\hline \multicolumn{7}{|l|}{ Quality of life (EQ-5D) } \\
\hline VAS & $64.7(4.4)$ & $73.1(4.0)$ & $72.3(3.1)$ & $65.0(4.5)$ & $69.3(4.9)$ & $62.4(3.5)$ \\
\hline Index & $0.76(0.03)$ & $0.8 \mathrm{I}(0.03)$ & $0.78(0.08)$ & $0.70(0.04)$ & $0.72(0.03)$ & $0.61(0.09)$ \\
\hline Subjective activity (BPAQ) & $7.1(0.4)$ & $6.5(0.4)$ & $7.2(0.4)$ & $6.1(0.4)$ & $6.7(0.4)$ & $6.2(0.4)$ \\
\hline $\begin{array}{l}\text { Objective activity (IMA; } \\
\text { counts per minute) }\end{array}$ & $536.3(42.6)$ & $556.7(43.4)$ & $511.0(44.1)$ & $360.5(44.7)$ & $381(45.1)$ & $335.2(46.3)$ \\
\hline
\end{tabular}

Abbreviations: 6MWT, 6-minute walking test; BPAQ, Baecke Physical Activity Questionnaire; CCQ, clinical COPD questionnaire; COPD, chronic obstructive pulmonary disease; EQ-5D, EuroQol; IMA, integrated modulus of body acceleration; m, meters; MFI, Multidimensional Fatigue Inventory (general fatigue scale); NA, not applicable; T0, inclusion; TI, I month; T2, 3 months; VAS, visual analogue scale.

sufficiently motivating or stimulating for doing exercises at home. The exercises were already familiar for the patients, as these are also used in regular care, and the schemes do not change very much over time. Providing these exercises online via a web portal might thus not have triggered patients enough to exercise. An alternative could be to incorporate motivational strategies, eg, by the use of gaming technologies, which can have a positive effect on motivation. ${ }^{30}$

Patients were satisfied with the received care of the telehealth program. Internet-based therapy in other patient groups scored remarkably lower (eg, 20.6 \pm 4.8 in online psychotherapy $^{31}$ to $24.5 \pm 4.8^{32}$ and $22.8 \pm 4.6^{31}$ for online cognitive behavioral therapy). The slightly lower satisfaction scores for the telehealth group compared to the usualcare group might be attributable to the frustrations some patients experienced with the activity coach. For example, some patients found it frustrating that it did not properly assess cycling, a very common activity in the Netherlands. This also has been reported earlier: Koff et al found low satisfaction scores for their activity sensor due to unreliable detection of slow walking, but high satisfaction for the telehealth program. ${ }^{33}$ Besides, interviews with patients after finishing the program showed that it is very important to manage the expectations of the patient regarding such a new intervention and how (often) this web portal is used by the health care professionals, eg, how often will the professional look into the data on the web portal and when will the professional take action? When the patients' expectations are in line with the received care, satisfaction is expected to increase too.

\section{Implications}

This pilot study provides important information for the implementation of a full study in daily care, ie, in terms of recruitment, randomization, follow-up assessment, and treatment. In this pilot, recruitment of patients was difficult, mainly because of the strict inclusion and exclusion criteria with a focus on patients with regular exacerbations, as well as the need of a computer with Internet access at home. In this age-group, the majority of people are not familiar with using the Internet, and as such worries about the use of the technology beforehand might have put the patients off and made recruitment more difficult. ${ }^{34}$

The study showed a high attrition rate. The strict criteria in relation to exacerbations/hospitalizations meant that the participants in general had a poor and unstable health status, especially in the control group, who had significantly worse dyspnea levels. A review by Beauchamp et al ${ }^{35}$ addressed this issue in supervised exercise programs after rehabilitation, where acute exacerbations and disease progression contributed to the high dropout rate, which was also shown in our study. However, we do assume that the poor clinical characteristics of our control group were an exception. In a previous large study with exactly the same criteria, ${ }^{19}$ both the intervention and control groups showed comparable lung function and even better dyspnea levels than the telehealth group of our study. For future studies, the baseline characteristics of participants lost to follow-up and those included in the analysis should be reported separately to help indicate possible attrition bias. ${ }^{36}$ Another option would be to also include patients with less frequent exacerbations. In this 
group, the intervention would also be very suitable, and patients could be taught to self-manage their exacerbations in an earlier stage of their disease.

The losses to follow-up, together with the temporary unavailability of one physiotherapy practice, were also a reason not all measurements were assessed. This made us unable to report the number of exacerbations in the control group, who had to fill in paper diaries for monitoring symptom levels. Alternatively, in future we could monitor symptom levels on a smartphone, where the patient automatically receives a message to fill in the diary.

In relation to the treatment, our study showed low adherence to the exercise and activity-coach modules. It is however very important to increase the use of these modules, since a higher usage of the activity coach has been shown to be significantly associated with an improvement in activity levels. ${ }^{22}$ Adherence might be increased by integrating these modules in a self-management program targeting both (post-) exacerbation strategies and activity behavior. ${ }^{37}$ In this way, the intervention would also target exercise self-efficacy and expected benefits from regular exercise, which are predictors of exercise adherence. ${ }^{27}$ In this program, the activity coach can support both patients and professionals by providing insight in daily activity behavior and providing tools for changing activity behavior in daily life.

With all this taken into account, in a larger-scale study, a broader group of patients could be recruited. We expect that when the majority of the patients in the care centers participate in the intervention program, to make it feel like standard care for the professionals, this would increase the use of the program of both patients and professionals. In relation to treatment, the exercise and activity-coach modules should also be incorporated in a self-management program to increase adherence, and in which the management of patient expectations is addressed. Besides, miniaturized sensors and gamification strategies could further improve satisfaction and increase motivation to use these modules. This future research should be directed toward effectiveness as well as costs versus benefits of this integrated telehealth program.

\section{Conclusion}

In conclusion, this was the first study to apply an integrated telehealth intervention as blended care in patients with COPD that consisted of a real-time ambulant activity coach, a web portal for self-treatment of exacerbations in COPD, an online exercise program, and teleconsultation. The telehealth program with decision support showed good satisfaction, and parts of the intervention were highly used. Health care providers seem to play an important role in patients' adherence to telehealth in usual care. Future research should focus on full-scale implementation in daily care. We would recommend 1) integrating all the modules in a standardized self-management program, in which management of patient expectations is addressed, and 2) investigating technological advances, like gaming, to increase adherence.

\section{Acknowledgments}

We thank the patients for their participation and feedback. We are grateful to the (medical) staff at the Department of Pulmonary Medicine of Medisch Spectrum Twente and the primary care physiotherapists for their active involvement in the study. Financial support was provided by the NL Agency, a division of the Dutch Ministry of Economic Affairs (grant CALLOP9089).

\section{Disclosure}

The authors report no conflicts of interest in this work.

\section{References}

1. Seemungal TA, Donaldson GC, Paul EA, Bestall JC, Jeffries DJ, Wedzicha JA. Effect of exacerbation on quality of life in patients with chronic obstructive pulmonary disease. Am J Respir Crit Care Med. 1998;157(5 Pt 1):1418-1422.

2. Domingo-Salvany A, Lamarca R, Ferrer M, et al. Health-related quality of life and mortality in male patients with chronic obstructive pulmonary disease. Am J Respir Crit Care Med. 2002;166(5):680-685.

3. Gosselink R, Langer D, Burtin C, et al. Clinical practice guideline for physical therapy in patients with COPD - practice guidelines. Suppl Dutch J Phys Ther. 2008;118(4):1-60.

4. Global initiative for chronic Obstructive Lung Disease. Global Strategy for the Diagnosis, Management, and Prevention of COPD. Bethesda (MD): GOLD; 2013.

5. Donaldson GC, Wilkinson TM, Hurst JR, Perera WR, Wedzicha JA. Exacerbations and time spent outdoors in chronic obstructive pulmonary disease. Am J Respir Crit Care Med. 2005;171(5):446-452.

6. O'Donnell DE, Parker CM. COPD exacerbations 3: Pathophysiology. Thorax. 2006;61(4):354-361.

7. Agusti A, Calverley PM, Celli B, et al. Characterisation of COPD heterogeneity in the ECLIPSE cohort. Respir Res. 2010;11:122.

8. Kessler R, Partridge MR, Miravitlles M, et al. Symptom variability in patients with severe COPD: a pan-European cross-sectional study. Eur Respir J. 2011;37(2):264-272.

9. Lacasse Y, Martin S, Lasserson TJ, Goldstein RS. Meta-analysis of respiratory rehabilitation in chronic obstructive pulmonary disease. A Cochrane systematic review. Eura Medicophy. 2007;43(4): 475-485.

10. Kruis AL, Smidt N, Assendelft WJ, et al. Integrated disease management interventions for patients with chronic obstructive pulmonary disease. Cochrane Database Syst Rev. 2013;10:CD009437.

11. Bourbeau J, Saad N. Integrated care model with self-management in chronic obstructive pulmonary disease: from family physicians to specialists. Chron Respir Dis. 2013;10(2):99-105.

12. Agusti A, Macnee W. The COPD control panel: towards personalised medicine in COPD. Thorax. 2013;68(7):687-690.

13. Nguyen HQ, Donesky D, Reinke LF, et al. Internet-based dyspnea selfmanagement support for patients with chronic obstructive pulmonary disease. J Pain Symptom Manage. 2013;46(1):43-55. 
14. Jensen MH, Cichosz SL, Hejlesen OK, et al. Clinical impact of home telemonitoring on patients with chronic obstructive pulmonary disease. Telemed J E Health. 2012;18(9):674-678.

15. Bolton CE, Waters CS, Peirce S, Elwyn G. Insufficient evidence of benefit: a systematic review of home telemonitoring for COPD. J Eval Clin Pract. 2011;17(6):1216-1222.

16. McLean S, Nurmatov U, Liu JL, Pagliari C, Car J, SheikhA. Telehealthcare for chronic obstructive pulmonary disease: Cochrane Review and meta-analysis. Br J Gen Pract. 2012;62(604):e739-e749.

17. Wootton R. Twenty years of telemedicine in chronic disease managementan evidence synthesis. J Telemed Telecare. 2012;18(4):211-220.

18. Huis in 't Veld RM, Kosterink SM, Barbe T, Lindegard A, Marecek T, Vollenbroek-Hutten MM. Relation between patient satisfaction, compliance and the clinical benefit of a teletreatment application for chronic pain. J Telemed Telecare. 2010;16(6):322-328.

19. Effing T, Kerstjens H, van der Valk P, Zielhuis G, van der Palen J. (Cost)-effectiveness of self-treatment of exacerbations on the severity of exacerbations in patients with COPD: the COPE II study. Thorax. 2009;64(11):956-962.

20. Effing T, Zielhuis G, Kerstjens H, van der Valk P, van der Palen J. Community based physiotherapeutic exercise in COPD self-management: a randomised controlled trial. Respir Med. 2011;105(3):418-426.

21. Tabak M, op den Akker H, Hermens H. Motivational cues as real-time feedback for changing daily activity behavior of patients with COPD. Patient Educ Couns. 2014;94(3):372-378.

22. Tabak M, Vollenbroek-Hutten MM, Van der Valk PDLPM, van der Palen J, Hermens HJ. A telerehabilitation intervention for patients with COPD: a randomized controlled pilot trial. Clin Rehabil. 2013;28(6):582-591.

23. Vollenbroek-Hutten MM, Hermens HJ, Kadefors R, Danneels L, Nieuwenhuis LJ, Hasenbring M. Telemedicine services: from idea to implementation. J Telemed Telecare. 2010;16(6):291-293.

24. Effing T, Kampshoff C, van der Valk PD, Kerstjens HA, Zielhuis GA, van der Palen J. Immediate in-hospital reactivation of patients with an exacerbation of COPD: PULMOFIT-MST. 2009. Available from: http:// www.trialregister.nl/trialreg/admin/rctview.asp?TC=1101. Accessed June 30, 2014.

25. Bouten CV. Assessment of Daily Physical Activity by Registration of Body Movement [doctoral thesis]. Eindhoven, Netherlands: Eindhoven University of Technology; 1995.
26. World Health Organization. Adherence to Long-Term Therapies Evidence for Action. Geneva: WHO; 2003.

27. Bourbeau J, Bartlett SJ. Patient adherence in COPD. Thorax. 2008;63(9): 831-838.

28. Horton $\mathrm{K}$. The use of telecare for people with chronic obstructive pulmonary disease: implications for management. J Nurs Manag. 2008;16(2):173-180.

29. Mair FS, Hiscock J, Beaton SC. Understanding factors that inhibit or promote the utilization of telecare in chronic lung disease. Chronic Illn. 2008;4(2):110-117.

30. Lange B, Flynn SM, Rizzo AA. Game-based telerehabilitation. Eur J Phys Rehabil Med. 2009;45(1):143-151.

31. Donker T, Bennett K, Bennett A, et al. Internet-delivered interpersonal psychotherapy versus internet-delivered cognitive behavioral therapy for adults with depressive symptoms: randomized controlled noninferiority trial. J Med Internet Res. 2013;15(5):e82.

32. Hedman E, Andersson E, Lindefors N, Andersson G, Ruck C, Ljotsson B. Cost-effectiveness and long-term effectiveness of internetbased cognitive behaviour therapy for severe health anxiety. Psychol Med. 2013;43(2):363-374.

33. Koff PB, Jones RH, Cashman JM, Voelkel NF, Vandivier RW. Proactive integrated care improves quality of life in patients with COPD. Eur Respir J. 2009;33(5):1031-1038.

34. Finkelstein SM, Speedie SM, Demiris G, Veen M, Lundgren JM, Potthoff S. Telehomecare: quality, perception, satisfaction. Telemed $J$ E Health. 2004;10(2):122-128.

35. Beauchamp MK, Evans R, Janaudis-Ferreira T, Goldstein RS, Brooks D. Systematic review of supervised exercise programs after pulmonary rehabilitation in individuals with COPD. Chest. 2013;144(4):1124-1133.

36. Dumville JC, Torgerson DJ, Hewitt CE. Reporting attrition in randomised controlled trials. BMJ. 2006;332(7547):969-971.

37. Spruit MA, Singh SJ, Garvey C, et al. An official American Thoracic Society/European Respiratory Society statement: key concepts and advances in pulmonary rehabilitation. Am J Respir Crit Care Med. 2013;188(8):e13-e64.
International Journal of COPD

\section{Publish your work in this journal}

The International Journal of COPD is an international, peer-reviewed journal of therapeutics and pharmacology focusing on concise rapid reporting of clinical studies and reviews in COPD. Special focus is given to the pathophysiological processes underlying the disease, intervention programs, patient focused education, and self management protocols.

\section{Dovepress}

This journal is indexed on PubMed Central, MedLine and CAS. The manuscript management system is completely online and includes a very quick and fair peer-review system, which is all easy to use. Visit http://www.dovepress.com/testimonials.php to read real quotes from published authors. 